\section{MENTAL HEALTH, UNEMPLOYMENT, TOBACCO, WASTE, AND PIGS}

In a bumper edition for summer, we include substantial contributions on two major threats to public health: tobacco and unemployment, and in addition we address the vexed issue of the role of psychosocial factors. All three topics are given a treatment that should generate a lively debate.

Starting with tobacco and the tobacco industry, a paper from Nicole Fields and Simon Chapman from Australia (Simon being the Editor of our sister journal, Tobacco Control) throws light on the scandalous efforts of the purveyors of death and disease and one of the major weapons of mass destruction, namely the tobacco industry, to exert undue influence on a leading scientist in the field of tobacco research, Ernst Wynder. Two linked editorials explore the questions raised, and in particular the responsibilities of academics and researchers in relation to funding sources. See pages 571, 546, 548

A paper by Blakely and colleagues from New Zealand, with a population of over two million, concludes that unemployment was associated with a twofold to threefold increased relative risk of death by suicide, compared with the employed. About half this association might be attributable to confounding by mental illness. The paper is accompanied by four commentaries, which explore the issue and the questions raised. See pages 594, 557-61

McCleod and Davey Smith have reviewed the psychosocial factors that affect public health and argue that, until there is better evidence, policy to reduce inequalities should be directed towards improving physiological and behavioural risk profiles and material circumstances. Singh-Manoux takes exception to McCleod and Davey Smith's approach, and argues that what could be an interesting discussion is compromised by the authors' implicit assumption that there is a single pathway linking social position to health when

\section{www.jech.com}

evidence supports multiple pathways. McCleod and Davey Smith provide a robust reply. Let the debate continue.

See pages $565,553-56$

These papers could make up an issue on their own, but there is plenty more to come. From El Salvador, our Gallery highlights the impact of health reforms on coverage of the poor and reminds of the role of pigs in many developing countries as a vector of parasitic and other disease. Speaker's Corner continues the debate about war in Iraq, with Braveman arguing that there are four consequences of war beyond the direct ones that need to be considered:

- massive aftershocks on the infrastructure, such as resulted in many more deaths after the end of the first Gulf War than during it;

- the establishment of a precedent for pre-emptive military strikes in defiance of the United Nations;

- an exacerbation of inequalities in health because of the differential impact of war and its sequelae on the poor, especially children; and, fourthly,

- the impact of what is happening on human rights globally.

Meanwhile, Garcia and Sanchez-Bayle raise concerns about the drift of European Union policy development with the introduction of the market into health care relations and its impact on equity. They argue for a Letter of the Rights to Health.

See pages $552,570,564,593$

An editorial on multilevel approaches to social epidemiology, linked to a research paper on pre-term birth, explores the impact of adverse neighbourhood conditions beyond that of cigarette smoking. And in our newly named section, Evidence Based Public Health Policy and Practice, there is evidence that smoking cessation services are reducing health inequalities in England.

See pages $550,606,579$

Other points from this issue include:

- findings from New Zealand that deprived communities are experiencing a disproportion burden of adverse health effects as a result of poor water quality;

- that relative health inequalities did not change or decrease during the recession years in Sweden (some of us may not be surprised, given the overall continuing welfare structure of that blessed country);

- the findings from a randomised controlled trial that providing women with evidence based information on the risks, uncertainties and benefits of cervical screening is likely to deter some, but not differentially those at higher risk;

- the impact of socioeconomic and relationship factors on the decision to have an abortion is not the same at different stages in life;

- the highly significant overall decline in male birth ratio in Europe and North America does not have a reasonably identified explanation, and the causes for these trends may be multi-factorial (I had assumed that this was something to do with the tendency to an older age of fathers);

- the effects of place of residence on mental health are greatest among those who are economically inactive, and therefore more likely to spend more time at home;

- existing gradients between the health of men and women and different social classes are maintained and probably exacerbated by the experience of acute illness (a heart attack).

See pages $581,584,589,601,612,616,622$

Two papers in our Theory and Methods section take forward the instruments for exploring the impact of mortality and temperature on health, and of adapting the Framingham methods for coronary heart disease risk to European Mediterranean areas.

See pages 628,634

We have taken the decision to develop a journal section on Continuing Professional Education, and this new section provides a home this month for the third and final part of our Glossary on genetic epidemiology. We will be developing the section, and ideas and contribution are welcome.

See page 562

Finally, Hygieia already seems like an established part of the journal. See page 640 